Western University

Scholarship@Western

Aboriginal Policy Research Consortium International (APRCi)

2011

\title{
Illuminating the Lived Experiences of Research with Indigenous Communities
}

Catherine E. Burnette

Sara Sanders

Howard K. Butcher

Emily Matt Salois

Follow this and additional works at: https://ir.lib.uwo.ca/aprci

Part of the Community-Based Research Commons

Citation of this paper:

Burnette, Catherine E.; Sanders, Sara; Butcher, Howard K.; and Salois, Emily Matt, "Illuminating the Lived Experiences of Research with Indigenous Communities" (2011). Aboriginal Policy Research Consortium International (APRCi). 171.

https://ir.lib.uwo.ca/aprci/171 
This article was downloaded by: [University of Western Ontario]

On: 18 November 2012, At: 07:03

Publisher: Routledge

Informa Ltd Registered in England and Wales Registered Number: 1072954 Registered office: Mortimer House, 37-41 Mortimer Street, London W1T 3J H, UK

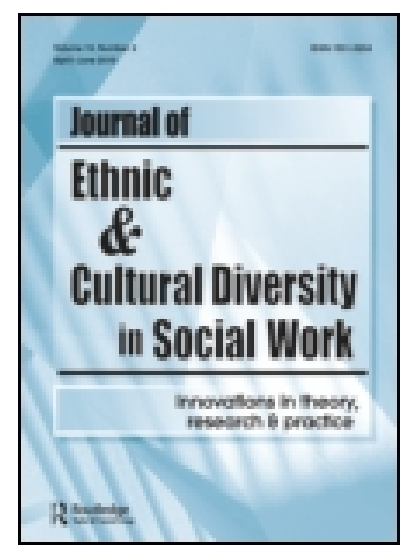

\title{
J ournal of Ethnic And Cultural Diversity in Social Work
}

Publication details, including instructions for authors and subscription information:

http:// www.tandfonline.com/loi/ wecd20

\section{Illuminating the Lived Experiences of Research with Indigenous Communities}

\author{
Catherine E. Burnette ${ }^{a}$, Sara Sanders ${ }^{a}$, Howard K. Butcher ${ }^{b} \&$ \\ Emily Matt Salois ${ }^{c}$ \\ a School of Social Work, University of Iowa, Iowa City, Iowa, United \\ States \\ ${ }^{b}$ College of Nursing, University of lowa, Iowa City, lowa, United \\ States \\ c Center for Native Health Partnerships, Montana State University, \\ Bozeman, Montana, United States \\ Version of record first published: 04 Nov 2011.
}

To cite this article: Catherine E. Burnette, Sara Sanders, Howard K. Butcher \& Emily Matt Salois (2011): Illuminating the Lived Experiences of Research with Indigenous Communities, J ournal of Ethnic And Cultural Diversity in Social Work, 20:4, 275-296

To link to this article: http:// dx.doi.org/ 10.1080/ 15313204.2011.622199

\section{PLEASE SCROLL DOWN FOR ARTICLE}

Full terms and conditions of use: http://www.tandfonline.com/page/terms-and-conditions

This article may be used for research, teaching, and private study purposes. Any substantial or systematic reproduction, redistribution, reselling, loan, sub-licensing, systematic supply, or distribution in any form to anyone is expressly forbidden.

The publisher does not give any warranty express or implied or make any representation that the contents will be complete or accurate or up to date. The accuracy of any instructions, formulae, and drug doses should be independently verified with primary sources. The publisher shall not be liable for any loss, actions, claims, proceedings, demand, or costs or damages whatsoever or howsoever caused arising directly or indirectly in connection with or arising out of the use of this material. 


\title{
Illuminating the Lived Experiences of Research with Indigenous Communities
}

\author{
CATHERINE E. BURNETTE and SARA SANDERS \\ School of Social Work, University of Iowa, Iowa City, Iowa, United States \\ HOWARD K. BUTCHER \\ College of Nursing, University of Iowa, Iowa City, Iowa, United States \\ EMILY MATT SALOIS \\ Center for Native Health Partnerships, Montana State University, Bozeman, \\ Montana, United States
}

The historical exploitation experienced by indigenous people in the United States has left a number of negative legacies, including distrust toward research. This distrust poses a barrier to progress made through culturally sensitive research. Given the complex history of research with indigenous groups, the purpose of this descriptive phenomenological study was to illuminate the lived experiences of both indigenous and non-indigenous researchers conducting culturally competent research with indigenous people. Interviews from 13 social science research experts revealed 6 underlying themes about their research with indigenous people, including respect and commitment, mutual trust, affirmation, harmony among multiple worldviews, responsibility, and spiritual/personal growth.

KEYWORDS research, indigenous, phenomenology, Native American

The authors wish to sincerely acknowledge the participants of this study. The cumulative expertise, information, and experiences provided by these researchers made this study possible. The generous time and thoughtfulness afforded by the participants was integral to its successful completion.

Address correspondence to Catherine E. Burnette, School of Social Work, University of Iowa, 308 North Hall, Iowa City, IA 52242, USA. E-mail: Catherine-burnette@uiowa.edu 


\section{INTRODUCTION}

The prevalent mental health disparities among indigenous people in the United States provide compelling evidence about the need for effective research to enhance the well-being of this group (National Institutes of Health, 2009). Higher rates of mental distress than all other ethnicities are reported for indigenous people, and substance dependence within this group is ranked second highest as compared with other ethnicities (Walls, 2006). The suicide rate among indigenous people has been reported at 190\% of the general population's (Office of the General Counsel, U.S. Commission on Civil Rights, 2004). The latest Native American Health Care Disparities Briefing stated that this group is the most isolated and deprived minority group as the result of the unfulfilled trust relationship in which the government promised to protect land, resources, and the health care of these people (Office of the General Counsel, U.S. Commission on Civil Rights, 2004). This special status makes the unmet service needs and the deficit in professionals to serve this group particularly concerning. In order for the United States to fulfill the trust agreement to provide for the health care and reduce the disparate mental distress that is reported among indigenous people, culturally competent research is needed. Weaver (1997) argues that although cultural competence for social work practitioners has been a focus in the literature, it is also essential for researchers to develop meaningful and culturally relevant research questions, methodology, and interpretations for indigenous groups. The author described cultural competence as encompassing knowledge of a specific group's culture and worldview, researchers' awareness of their own cultural values and biases, and applying appropriate research intervention strategies (Weaver, 1997). Because research has been conducted in ways that have exploited and caused harm to indigenous people, however, trust relations between researchers and indigenous people is understandably impaired. Impaired trust adds a layer of complexity to conducting research with indigenous people. Until this complexity is understood, progress toward culturally sensitive research to address the disproportionate disparities that are experienced within this group is impeded.

To disentangle the complexity of conducting research with indigenous people, greater understanding of the lived experiences of researchers who work in this area is needed. For this reason, the purpose of this descriptive phenomenological study is to illuminate the experiences of both indigenous and non-indigenous researchers doing research with indigenous communities. This knowledge could help research progress toward the improved well-being of indigenous people who reside in the United States. The current state of research with indigenous communities is one part of the larger historical context. To understand how research with indigenous communities is situated within this larger context, it is important to consider significant 


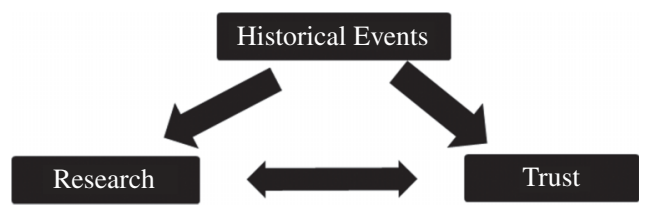

FIGURE 1 History, trust, and research with indigenous groups.

historical events throughout U.S. history and how these events impact trust and current research relationships. Figure 1 displays the effect of history on research and trust relationships with indigenous groups, along with the interplay between the resultant trust and research relationships. Historical events such as corrupt treaty relations, forced relocation to reservations, and the boarding school era have adversely affected trust and research relations with researchers and non-indigenous people. Because of history, along with culturally incongruent research practices, there is greater risk of exploitation experienced by indigenous people when interacting with non-indigenous persons and engaging in research. The continuous interplay between trust and research relations results.

\section{LITERATURE REVIEW}

\section{Historical Context}

Upon the entrance of European settlers to the United States, foreign disease and alcohol were introduced to indigenous people. Because they had little immunity or tolerance for these unfamiliar substances, the result was a rise in addiction and sickness among indigenous people (Brave Heart \& DeBruyn, 1998). As disease caused their population in the United States to dwindle, the European settler population and resultant power increased (Banner, 2005). With this power imbalance, corrupt tactics were often used by non-indigenous people in the signing of treaties. Taking a larger parcel of land than what was agreed upon, having unauthorized tribal members make treaty decisions for the entire tribe, and the use of alcohol were deceptive tactics that were frequently used in the signing of treaties; oftentimes, these treaties were later broken by Colonial and U.S. governments.

Foreign disease as well as genocide, which is defined as systematic efforts to eradicate in whole or in part a specific ethnic, racial, or national group (Legters, 1988), reduced the original indigenous population by an estimated $80 \%$ to $99 \%$ (Garrett \& Pichette, 2000; Weaver, 1998). Following military defeat, indigenous Americans were forced to relocate to land reservations where there was starvation, desertion, and prohibition of engagement in the cultural practices that were integral to their mental, spiritual, and physical well-being (Whitbeck, Adams, Hoyt, \& Chen, 2004). This 
ethnic cleansing continued in the boarding school era that began in 1878, which forced assimilation among indigenous youths. Some children were beaten for speaking their native tongue, and/or were physically, emotionally, and sexually abused, and many died from disease (Brave Heart, 1999; Brave Heart \& DeBruyn, 1998).

Historical trauma is a concept that has emerged among the literature on indigenous communities to describe the effect of the collective and chronic traumatic events that are inflicted upon a group of people over generations. Historical trauma has been linked by many researchers to the compromised well-being and mental health experienced by indigenous people in the United States (Brave Heart, 1999; Brave Heart \& DeBruyn, 1998; Fisher \& Ball, 2003). In Whitbeck et al.'s (2004) contemporary study measuring historical trauma, numerous losses were perceived among indigenous people, including the loss of family ties because of family separation during the boarding school era and the loss of trust in whites because of broken treaties. In addition, discomfort, fear, and distrust toward the intentions of white people were among the most common historical loss symptoms. This distrust dates back to Colonial times, when a 1790s' diplomat explained to George Washington that indigenous people had so often been deceived by whites (Banner, 2005), "that White Man is, among many of them [indigenous people], but another name for Liar" (p. 140). It is clear to see how this distrust from historical events extends to relations between indigenous communities and non-indigenous researchers. Because the events that gave rise to historical trauma conjure up distrust toward researchers who may be white themselves, researchers are often met with understandable suspicion.

\section{Research and Trust}

Mistrust of research does not only stem from historical trauma. Because of past exploitation and culturally inappropriate methodology (Caldwell et al., 2005; Weaver, 1997), research conjures up distrust and is considered a "dirty" word for many indigenous communities (Letiecq \& Bailey, 2004; Smith, 1999). The objective and removed stance that is standard for quantitative research methods may be considered rude and inappropriate to indigenous communities where interpersonal interaction is paramount (Weaver, 1997). Exploitation has compounded the mistrust toward research; an example of this is when some Havasupai tribal citizens gave blood samples to Arizona State University for the sole purpose of curbing the high rates of diabetes, and the samples were used in other unauthorized studies having to do with schizophrenia and inbreeding (Capriccioso, 2010).

In addition, research tends to be situated within educational systems, which have a history of legitimizing dehumanizing Colonial views about 
indigenous people (Smith, 1999). History has largely been written about indigenous people from a non-indigenous, Eurocentric perspective. The writers of history include bureaucrats and philosophers who have expressed harmful and prejudicial descriptions of indigenous people as "savages" (Banner, 2005). This discourse has been translated through educational systems and books (Smith, 1999). This inaccurate depiction of history, along with the aforementioned educational experiences of the boarding school era that attempted to "civilize" indigenous children, has given rise to reasonable mistrust of academia and the research that is often initiated within educational institutions (Smith, 1999).

Multiple layers of trust and mistrust throughout the many systems involved in research are at the center of this interplay between researchers and indigenous groups (Christopher, Watts, McGormic, \& Young, 2008). According to Kollock, people are routinely faced with situations where they could benefit from social interaction, but this interaction can also make them vulnerable to exploitation (1994). If uncertainty, risk, or vulnerability to exploitation is too high, trust may not emerge to foster social interaction (Kollock, 1994). Given the history of harmful research practices, the uncertainty of social interaction with non-indigenous researchers might be a risk too great for some indigenous communities. If indigenous communities and researchers do not interact, however, the benefits of culturally sound research collaboration may not be attained (Yamagishi, Cook, \& Watabe, 1998). Because the number of highly trained indigenous professionals is insufficient to meet the unmet research and service needs of this group, non-indigenous researchers and practitioners are needed (Whitbeck, 2009). Despite the need for culturally sensitive research, mistrust and past harm create barriers between researchers and indigenous people. This barrier blocks the interchange that could lead to collaboration and culturally sound research, which may improve the well-being of indigenous people.

Most literature on research and indigenous communities focuses on culturally appropriate research methods (Caldwell et al., 2005; Fisher \& Ball, 2003, 2005; Holkup et al., 2009; Letiecq \& Bailey, 2004; Salois \& Holkup, 2006; Weaver, 1997). Although this is essential information, there is little research on the intentions of indigenous and non-indigenous researchers who work with indigenous people and what they actually experience. Potential researchers who think they may want to pursue research with indigenous people can use this illustration to learn from the experiences of culturally competent researchers and gauge whether research with indigenous people is an appropriate match for them. The importance of this cannot be overlooked, because a lack of fit may contribute to inappropriate methodology, cultural blunders, and further harm to indigenous people. This information also provides important implications for academic and 
funding institutions about what is entailed in indigenous research and ways to foster cultural sensitivity.

\section{METHODS}

The purpose of this descriptive phenomenological study was to illuminate the lived experiences of researchers working with indigenous communities. Lived experience encompasses the natural, pre-reflected experience of people before it is reflected on or abstracted (van Manen, 1990). Phenomenology is well suited to understand existential features of human experience and is a method initially developed by the philosopher Husserl (Dowling, 2007). The term phenomenology was used as early as 1765 in Kant's philosophical writings and was further delineated by Hegel, who considered phenomenology to be knowledge that appears in consciousness (Moustakas, 1994). Phenomenological research seeks to describe the essence of lived experience as it exists through the lens of the subjective perceptions of people. Any phenomenon that enters consciousness can be the subject of inquiry, and phenomenological research is well suited to understand what a particular experience is like-in this case, research with indigenous communities (van Manen, 1990). Phenomenology uncovers both universal experiences across people as well as the particularity of experiences for individuals. It is not about comparisons between groups, but rather reveals underlying structure that emerges across experiences, while honoring individual stories. The approach is aimed at uncovering the essential parts of lived experiences of a particular group of people (Lopez \& Willis, 2004; Groenewald, 2004; Starks \& Brown Trinidad, 2007). For the purpose of this study, Clark Moustakas's method, a contemporary adaptation to Husserl's method, was employed (Moustakas, 1994).

The phenomenological approach has been used in the past to understand the delicate interplay of the experiences of a white researcher with indigenous groups (Dé Ishtar, 2004). Because it utilizes the oral tradition of storytelling, literature has posed that phenomenology is an appropriate research method for indigenous people (Struthers \& PedenMcAlpine, 2005). This method also makes use of experience that is in context, which safeguards information from being distorted. There is no literature about research with indigenous communities that uses a phenomenological approach to understand the experience and meaning of both indigenous and non-indigenous researchers. Because both groups are performing this research, the inclusion of both groups is essential for a complete understanding. In accord with phenomenological research, this study will uncover the universals among all researchers while honoring the specific individual experiences. For these reasons, the following research question was employed: What are the lived experiences of indigenous and non-indigenous researchers working with indigenous groups? 


\section{Sample}

The key inclusion criterion for this purposive sample was participants who had experienced the phenomenon of social science research with indigenous people. These experts in the research field were chosen due to their success in conducting social science research with indigenous people. Many researchers had published literature on the unique considerations of working with indigenous groups and ways to conduct research in a communitybased and culturally relevant way. Performing a literature review for this project provided the names of many authors who had conducted credible and culturally sensitive social science research with indigenous communities. Authors from articles along with their respective reference sections were the primary source of participant recruitment. During the interview process, some participants recommended other researchers for participation; these participants were also followed up with and screened for inclusion. We used the university Web sites of the researchers who worked with indigenous communities to gain their contact information.

Local Institutional Review Board (IRB) approval was received on April 16, 2010. Although a sample size of 10 thorough interviews is thought to result in an adequate saturation (Creswell, 1998), literature stated that sample sizes for phenomenological studies appropriately range from 1 to 20 participants (Groenewald, 2004; Starks \& Brown Trinidad, 2007; Wilson \& Hutchinson, 1991). After the initial recruiting e-mail was sent out, 13 researchers responded and consented to complete interviews. Interviews were conducted until saturation was met, and no new information was gained from them. Saturation was reached by the completion of 11 interviews, and 2 additional interviews were completed beyond this. All 13 participants conducted social science research. Seven participants were scholars in the areas of social work, and the remaining were scholars in psychology, public health, health and human development, counseling, nursing, and political science. Researchers practiced a diverse array of research methodology that ranged across the spectrum of quantitative and qualitative practices. Participants' ages were reported from 39 to 70, and researchers' experience ranged from 15 to 37 years. Participants resided across the contiguous U.S. states as well as Hawaii. There were seven non-indigenous and six indigenous researchers in this study.

\section{Data Collection Procedures}

In phenomenological research, interviews are reciprocal and mutually engaging (Groenewald, 2004; Wilson \& Hutchinson, 1991). According to Moustakas (1994), participants are considered co-researchers; in the case of this study, because the sample was composed of actual researchers, this was the literal case. The primary researcher held six in-person and seven phone 
interviews. Because participants resided in states across the United States, in-person interviews were not feasible for all participants. Taped interviews lasted an average of 47 minutes. Consistent with descriptive phenomenology, the data were used to uncover the essence of this experience, rather than explanation or analysis (Creswell, 2007; Moustakas, 1994). Prior to the interview, the researcher attempted to bracket or set aside preconceived biases and ideas about the topic (Moustakas, 1994). This enabled the interviewer to begin the interview with a fresh and open perspective to whatever the participants presented. Data were collected using an open-ended semistructured interview guide to provide focus for the interview without being overly structured (Kvale, 1983; Moustakas, 1994). Examples of questions posed to participants included, "Take a moment to think about an early memory of your beginning research with people of indigenous descent. . . Describe this experience completely" and "How has research with people of indigenous descent affected you?"

During the interview, creating a comfortable environment for participants to openly describe their experiences was the primary goal of the principal researcher. When the interview came to a natural end, participants were given the opportunity to add any other relevant information. At the close of the interview, participants were informed about the remaining steps to the research process and invited to contact the researcher with additional questions or information. All participants were contacted for the opportunity to do member checks. Participants were informed that in the event that they were not able to respond to the member check, the presented analysis would be assumed to be non-problematic. In addition to interviews, the principal researcher took notes during the interview to highlight particularly meaningful statements along with personal reflections. The principal researcher kept a journal throughout the project to guard against researcher bias. For immersion and to foster greater understanding of indigenous communities, the principal investigator, who was of non-indigenous descent, also engaged in cultural education, attended a conference that focused on indigenous families, engaged in volunteer work, and visited numerous reservations.

\section{Data Analysis Techniques}

Interviews were listened to, and transcriptions were read through 3 to 4 times to gain a sense of their meaning as a whole. Analysis of the data was completed by two researchers. Researchers met after each analysis step for consultation and to reach consensus on findings. Analysis followed Moustakas's guidelines, which are a modification of van Kaam's method of analyzing phenomenological data (Moustakas, 1994). This method has been used in other studies and is useful by providing concise steps that enhance the rigor of the analysis process (Gilstrap, 2007; Liu, 2008). 
Moustakas's steps for each research participant were as follows (Moustakas, 1994):

1. Horizontalization was performed by listing every relevant statement.

2. Reduction and elimination was performed by removing repetitive, overlapping, or vague statements. The statements that could be abstracted were retained. This resulting list included 296 invariant meaning units, or essential parts of the experience.

3. These meaning units were clustered and relabeled into six overarching or core themes of the experience that were present among all research participants.

4. The invariant meaning units and themes were checked to the participant's transcribed interview as a whole, and all were either expressed explicitly by the respondent or were compatible with what the respondent said. These themes and supporting quotes were distributed to a fellow research team member, who spent more than 10 hours reviewing them. This team member had questions about two themes. After discussion, consensus on the themes was reached.

5. These validated meaning units and themes were used to create comprehensive descriptions of each participant's experience using verbatim quotes from interviews.

6. These descriptions were presented to each participant for the opportunity to do member checks. Of the seven participants who replied, there were no disagreements with overarching themes. One researcher offered suggestions to bring the wording of themes in line with indigenous concepts. These amended themes were checked with fellow research team members along with an indigenous participant and incorporated thereafter. Four participants added to or amended their initial quotes for meaning clarification.

7. Once consensus was reached among participants and researchers, a synthesis, or composite description, of all of the participants' experiences was created; this description maintained the individual components while describing the fundamental themes that were present among all participants. To safeguard against publishing harmful information, an indigenous cultural reader reviewed this description.

\section{Strategies for Establishing Scientific Rigor}

The following standards for scientific rigor in phenomenology were used for this study including descriptive vividness, methodological congruence, analytical preciseness, theoretical connectedness, and heuristic connectedness (Burns, 1989). The standard of descriptive vividness was met in this study by the explicit descriptions of the sample, recruitment, and analysis 
process. The standard of methodological congruence was met by rigor in documentation, procedural rigor, ethical rigor, and providing an audit trail, or auditability. Documentation rigor was met by explicitly describing the parts of the study, including the phenomenon, purpose, and the other essential parts. Procedural rigor was met by using explicit steps on data collection, using transcribed interviews, and analyzing using Moustakas's explicit steps. An audit trail with documents captured each step of the data analysis. Theoretical preciseness was intrinsic in the data analysis steps by checking to see whether the themes and invariant units were present and compatible with the verbatim text of the participants. Theoretical connectedness and relationship to existing body of knowledge was met by performing member checks, using a cultural reader, and seeing whether findings are compatible with the information in the literature review. The extensive member-checking process ensured a validation of themes, and suggestions from participants were incorporated into the naming of the themes. Heuristic relevance, or how applicable findings were, was met by the study providing needed insight for future and current researchers to enhance their practice along with useful information for funding agencies and the academic world.

\section{RESULTS}

Six core themes emerged from the phenomenological analysis. Each of the following core themes was present in each of the 13 participant descriptions of their experience.

\section{Cultivating Deep Respect and Commitment}

Researchers expressed a deep respect for the indigenous groups with whom they worked. This respect led to a profound personal commitment to this group. For some, this respect and commitment stemmed from the researchers being of indigenous descent, stating it was "because of my ancestry." As one researcher put it, "I have a vested interest in this. I'm not an outside researcher. I'm researching in my own community." Indigenous researchers spoke of their effort that transcended the conventional domains of work. One stated, "I'm committed to it [research] because it's about the future well-being of, um, of indigenous peoples. . . . I really didn't choose to do ... research with the indigenous communities. I was given that responsibility I think the moment I entered into academia." Another researcher related, "I really think that, um, I never chose research. It chose me." This researcher was compelled to do this work from experiencing research in her indigenous community that was done in an exploitative way. She stated, "I actually think we were-we were victims of research." This researcher 
experienced firsthand the effects of culturally insensitive research that many indigenous persons have felt. She stated, "Sometimes people [researchers] would come in and um, never come back." This, along with instances of the publishing of biased information, contributed to this researcher's initial impression that "research" was a "dirty" word.

For other researchers, respect for indigenous groups developed over time and with experience. Many researchers mentioned a long-term time commitment as part of this process. One non-indigenous researcher related, "We're in it for the long haul." Many researchers spoke about the refreshing aspect of humor in indigenous communities. A researcher remarked on this, "sense of humor. Because it's - I've grown to appreciate the-the amount of laughter that goes on in the reservations, which has been great." Another researcher spent time doing social work advocacy and practice, and this experience had a profound impact on his respect and commitment to this group. He related, "I got accepted in these communities ... they got to be my friends. They were like family." This researcher explained, "I specifically went to get my PhD, I think, because of the experiences I had in these communities.”

\section{Building Mutual Trust}

Researchers described a mutual trust that developed through relationships over time. One indigenous researcher related that after attending a university, it took 18 months for him to rebuild trust and become accepted back into his own community. He described the thinking of his community members. "Can we trust them? Can we trust her? He's been away for too long, you know, doing all this university stuff, and we don't know if he is changed." Another indigenous researcher experienced some initial resistance because, "I don't look indigenous." Through relationship building and doing community-based research, however, she received "an indication that I was trusted." She related an indigenous person stating, "You know, we trust you ... so we know that you would not send anybody to us that was not trustworthy." With mutual trust came reciprocity. One researcher explained, "They see that I'm trying to help the community, so they're trying to help me." Reciprocity between indigenous and non-indigenous colleagues was also acknowledged by stating, "We learn a lot from each other."

Researchers reported the importance of intent and being authentic in encounters with indigenous people. As one researcher described, "I just simply have to go in with a sense of honest goodwill, genuineness on my part." Whether researchers were non-indigenous or indigenous, cross-cultural understanding was important when learning about community other than their own. One researcher explained, "Because we can never completely understand or know another, essentially every encounter is a cross-cultural encounter." She added, "When faced with limited understanding, true 
intimacy comes from continuing to reach out to the other with the genuine desire to understand." The importance of intent was expressed by other researchers. "You know, in the final analysis, whether or not you're interested in them as people becomes the key relational component." This researcher added, "They're very accepting if you are willing to accept them. ... Your color may not match the population you're studying ... just remember, there's a two-way street. They want to learn about you as much as you want to learn about them."

\section{Creating Affirmation Through Relationships}

Relationships led to many researchers feeling affirmed in their work with indigenous communities. One researcher described a huge reward from his work:"to be honest, it's just been getting to know these men . . . and feeling very welcome now, and being invited into their-into their homes and into their culture and lives." Another researcher related a similar comment. "I had the opportunity to develop, you know, really strong relationships with-with the community leaders and community people. And so it's been incredibly rewarding as a result." Relationships and, as one researcher put it, "being more accepted," were common sentiments of researchers working with indigenous groups.

This affirmation through relationships extended to profound experiences for some researchers. One indigenous researcher related a time when an elder from the same tribal nation gave her a basket that she had made from sweetgrass. The elder stated, "You should have this basket, my gift to you." This was especially meaningful because this researcher didn't "look indigenous," and the elder's understanding and validation dispelled the need for this researcher to defend her indigenous background. Another indigenous researcher described an experience where she saw a project to fruition. Unlike the harmful researchers of the past, she went back to the community and reported the results. Community members then embraced her for her sound work. She recalled, "... this young man came in and he gave me tobacco, and I almost cried because tobacco is something that you give a healer, I mean, you know if you want prayers or healing."

Affirmation was also experienced by researchers who saw projects to fruition and witnessed community members reach their goals. One researcher reflected on a project in which he collaborated with indigenous men: "All the time and effort and energy that the men put into that event ... it was a lot of work, and they did the work." One indigenous researcher persevered in working with a group that faced multiple challenges. "I feel good that I didn't give up on that, even though there were setbacks ... I think probably the population that is acting out the most is the population that needs the most help. And I want to keep trying and I want to keep reaching this population." 


\section{Finding Harmony among Multiple Worldviews}

Indigenous and non-indigenous researchers remarked on finding harmony amid multiple worldviews. Finding balance between multiple researchers, the academic world, and indigenous communities took a great deal of energy. One researcher described this area of balance: "I was kind of there in the middle and we started calling it 'credibility stress'." To reduce the risk of causing harm to indigenous communities, research team members described how they "decided to draw up a memorandum of understanding." In this memorandum, they outlined "who owns the data." They also decided that "We cannot publish anything without having it go through the entire research team ... so we would not inadvertently say something that could be harmful." Within the research world there was the balance between contrasting ideas about the purpose and methodology of research itself. One researcher noted how many people believe "we need to approach things in a positivist way, and also, there's this need for comparison." She noted how colleagues had questioned whether she would compare data from the multiple communities with whom she had worked. This comparison, however, clashed with the goal of the community-based participatory work, which was "to meet that community's needs."

The added polarity between the qualitative and quantitative paradigms was also described. "The challenge is-is even more interesting with native or indigenous communities because they tend to be a lot more qualitative. ... I think there's a reason for that. I think, I think because a lot of indigenous people have lost their voices." This researcher felt that qualitative research "Gives indigenous people the opportunity to talk their story." A challenge in this arena was expressed. "How do you convert the story into ... the attention span of a funder?" This researcher went on to add, "There is a huge imbalance, I think; and we're trying to find the narrative. ... Because there is a third narrative sitting between these-these two paradigms. ... How do we connect the story and the ... statistics? ... That's the challenge."

Along with finding the connection between divergent research goals, researchers also spoke about finding harmony between the indigenous and academic norms. When community ceremonies took precedence over research activities, this could come in conflict with academic standards. One researcher related the importance of being prepared for an instance such as "showing up in a village and finding out, well a priest is in town, and nothing that you planned on happening is going to happen." One researcher gave the example of when multiple communities were receiving the same intervention. Due to a death in the community, there could be a time lapse in those receiving interventions. This researcher pointed out, "How in the world [do] you present that to funding services, 'Oh my work isn't going to be comparable across sites'?" Another researcher added, "When you do 
research that is more fluid, or that needs to be more fluid based on the population in which you're serving, it can be difficult in academia then to get your work recognized." This researcher explained, "We go out to communities to try and collect the data, uh, we-we can't isolate things quite as neatly and nicely as you might be able to in a lab." In relation to this, one researcher recounted the sentiments of indigenous elders: "The problem with Western science is that they cannot accept-they don't know how to deal with, uh multiple realities."

The intricacy of creating space for some researchers' indigenous community responsibilities and academic responsibilities was also described. "The balance is - is quite a challenge to live in both worlds." This indigenous researcher added, "How do I honor my responsibilities as an indigenous person, you know, getting to different ceremonies with a calendar that fills up with faculty meetings?" This was particularly difficult because her indigenous commitments followed aspects of natural life cycles, and "they're not something that can be printed on a calendar a year ahead of time." Another indigenous researcher related, "I always prayed that an education wouldn't betray my traditions." She added, "But it's hard to walk in two worlds and to do it gracefully, [that] is-is another thing."

Some researchers used their unique position to translate between indigenous and non-indigenous persons. One researcher explained that she was "well positioned to speak to non-indigenous people and educate them" about indigenous communities. A non-indigenous researcher explained that his work "placed me in a position" to "figure out the best ways" to translate between indigenous communities and decision-making bodies including "state line youth commissions, to legislators, to congressional folks," who "need a certain level of education." An indigenous researcher explained that "There are very important roles for non-natives. There is such a huge power imbalance between natives and non-natives in this society. To the point, you know, native people are ignored almost all the time." She added, "When we have non-native voices standing up for native concerns, then we're not such a tiny minority." This researcher expressed that non-indigenous persons can say to those in power, "It's important to consider these different issues, because it's not just a native issue, it's a human issue." She stated, "It is people that are more a part of mainstream society, people that are likely to be viewed as constituents and voters. And people that, um, that people in power are more used to listening to." Advocating for a worldview and life way that was largely devalued by the dominant society was described. "The forces are so imbalanced that it you know, those are the challenges." This researcher thought that the community culture was deemed insignificant by the dominant society but was "totally significant culturally."

One indigenous researcher remarked on a controversial area, stating that as indigenous people "start to revitalize their own sense of identity and language, there's an increasing resentment for colonization." This could 
transmit into an "anti-white sentiment." The researcher explained, "That creates an interesting dilemma. Um, they only want [indigenous group's name] to do [indigenous group's name's] research." The researcher explained that thinking that only indigenous researchers should conduct indigenous research extended across the globe. He felt that this perspective was "creating barriers to knowledge ... I don't think in the best interest of the culture."

Despite significant challenges, indigenous researchers commented on the benefits of finding harmony among the indigenous and non-indigenous domains. One researcher explained, "Balance is an ongoing theme throughout so many indigenous cultures. This is something that we always strive for." This delicate path was not something that could be "achieved" but was an ongoing endeavor. A researcher explained, "You are a stronger healthier person if you can negotiate both worlds. ... It's very challenging because the dominant society, by and large, barely recognizes that we have indigenous societies and cultures. So there will be constant clashing." Benefits of this negotiation were acknowledged by a researcher who stated, "It's the best decision I ever made."

\section{Assuming Personal Responsibility}

With the awareness of research that had done harm to indigenous groups, researchers expressed a high degree of personal responsibility in working with indigenous groups. One researcher described the impact of past research on his own experience: "The history is horrible. ... I had an experience where I'd really felt like the sins of all white researchers were placed upon my shoulders and-and people were treating me like that." This researcher understood this burden and wavered between feeling defensive and responsible for this history. He stated, "I think in a way it is [his responsibility]. Those were my ancestors. I'm not a native person, I'm a white person."

One researcher described her experience: "It's just a fine line to walk . . . it feels like there's a lot of responsibility that goes in with doing this research." This responsibility was highlighted when one researcher was collaborating with indigenous and non-indigenous researchers who published what this researcher later realized was "perpetuating negative stereotypes." This experience helped the researcher to develop more cultural sensitivity. She stated, "I try to be a lot more sensitive . . . and I try to be much more careful about the messages coming out of my research projects." One non-indigenous researcher reflected on the responsibility required to do indigenous research: "I think that you have to have really clear, um, ethical core principles about how you are doing the research." Part of this personal accountability was being willing to "show up," and to go that extra distance to meet indigenous community members on their terms. 
Many researchers spoke about traveling long distances and the extra time required to work with indigenous communities. As one researcher put it, "It's a long drive; it's difficult to establish trust in relationships." Another researcher noted that indigenous communities feel "if you can't make the effort to come to us, you know, then why should we work with you? You know that ... you have to come, you have to be here, you have to, you know, um be respectful and meet us and understand us, and understand our world." The time it took to do this research was also described: "It was really a slow process." This researcher added the importance of being perseverant and committed through his lengthy process. An indigenous researcher who did work in her own community related how community members didn't "really hold you professionally accountable but personally and even intergenerationally." Another indigenous researcher related the similar sentiments of community members with some humor: "If he writes something really awful about our community we will always know where he lives, and we will find him, and you know, we will make life difficult."

\section{Growing Spiritually and Personally}

Researchers commented on how their work had enriched their lives. A nonindigenous researcher stated, "I think it's really broadened my thinking . . . and really forced me to think about the, uh importance of a cultural context in research." She also described becoming "appreciative ... of that rich history" and aware of "the pervasiveness of stressors and things, but also the cultural strengths." One researcher found that "people are more alike than they are different. That adage hits home every day." Another researcher related, "It had a profound effect on me, not only as a researcher, but as an individual and as a person."

One indigenous researcher stated, "It's been a spiritual journey," and, "It's opened my eyes to a lot of things." Another researcher related, "I think there has been some reminders to me and to growth in my own-my own spirit about culture itself." A researcher summarized the effects of this work in a demonstrative way: "It's completely impacted me personally, emotionally, how I've grown as an individual . . . and it made me question my own worldviews . . . what I saw as reality . . . certainly what I saw as valuable." He added, "Aside from personal relationships like meeting my wife, and things like that, it's probably been the most important thing that's ever happened to me. ... And it's all good-even the painful stuff. Yeah, I feel lucky."

\section{DISCUSSION}

The sentiments of researchers working with indigenous groups were profound and revealing. One striking finding was that despite a challenging 
history of research with indigenous groups, researchers involved in this study developed powerful connections with indigenous communities. Researchers validated the notion that emerged from the literature that historical factors and trust formation are at the center of performing research with indigenous people and provided vivid illustrations of many of the complex factors that were present when engaging in this work. Because of historical exploitation, interactions between indigenous people and researchers were marked by risk and uncertainty. Over time, this track record of exploitative research in exchange relationships translated into research being perceived as a "dirty" word.

Kollock (1994) found that elevated risk and uncertainty in social interactions promoted high levels of interpersonal trust. This high level of trust was evident in the experiences described by participants. Kollock found that participants in an uncertain exchange condition were highly disturbed when they were betrayed, but strong connections and friendships were forged if an exchange partner proved trustworthy. In the case of researchers who had found success in conducting research with indigenous people, it was evident that profoundly strong connections developed. The results from this study validated and demonstrated the meaning and connection that can emerge when people involved in risky interpersonal interactions demonstrate trustworthiness. Part of the trustworthiness that researchers demonstrated was being willing to go the extra distance and exhibit a deep commitment to the indigenous communities that they served.

Central themes such as cultivating deep respect and commitment, building mutual trust, creating affirmation through relationships, finding harmony among multiple worldviews, assuming personal responsibility, and growing spiritually and personally were highlighted by all participants. Because this was a phenomenological study, the common underlying essences of all participants' experience, rather than comparing the differences between indigenous and non-indigenous researchers, were central. This was not to minimize the differences that emerged across indigenous and nonindigenous participants. In fact, a benefit of using a phenomenological method is that it enabled researchers to capture underlying essences while maintaining the individual stories and perspectives. A striking finding was that the underlying themes were consistent across both indigenous and nonindigenous researchers. Variations between indigenous and non-indigenous researchers did not emerge in regards to the essential themes, but rather dimensions of these themes. For instance, in the cultivating deep respect and commitment theme, both indigenous and non-indigenous participants described their respect for and commitment to indigenous groups. The reasons for this respect and commitment, however, differed, with indigenous researchers identifying their ancestry as central to their commitment and non-indigenous researchers stating respect and commitment developing from their experience in indigenous communities. 
Building mutual trust was another common theme, and this was something that was ongoing and present for both indigenous and non-indigenous researchers. Researchers stated being invested in this work long-term and that relationships were central to reciprocal collaboration and trust. Solid relationships and mutual trust were built upon authenticity, pure intent, and a sincere interest in indigenous people. These relationships enabled researchers to feel affirmed and accepted by indigenous community members. Being embraced and trusted by indigenous communities and with persevering despite challenges led researchers to feel rewarded. Finding harmony among numerous realms was also highlighted by researchers. These realms include the academic world and the indigenous community, ideas about the purpose and process of research, quantitative and qualitative methods, and indigenous and non-indigenous people. Though finding harmony among all of these factors was a challenge, it was essential for success in researchers' respective worlds.

The history of exploitation that indigenous communities have faced placed an added responsibility on researchers in this arena. Harmful past research placed the added burden on researchers, who had to prove their authenticity and intent. This is a logical consequence of past and current transgressions on indigenous groups and may have led to the especially strong relations that were forged. The additional sacrifice and responsibility in working with indigenous groups gave rise to the personal and spiritual growth that researchers experienced. Many researchers expressed having their perspective and awareness enhanced, and indigenous researchers spoke about the spiritual nature of their journey.

\section{Implications}

These findings provide researchers, academia, and funding agencies with a rich description of what work with indigenous communities is like. Researchers expressed strain in trying to find harmony among competing demands. It was apparent that although the challenges and complexities of this type of work were high, so too were the advantages and rewards of this work for researchers. The purpose and standards of conventional research often did not fit for work with indigenous groups. This was largely because research had traditionally been conducted from a Western, Eurocentric worldview, which often clashed with the indigenous worldview. To balance this bias, researchers can collaborate with indigenous institutions, such as tribal colleges, to conduct research in a culturally respectful way. Because reciprocity is a fundamental value among indigenous groups, research grants should be written in a way so that tribal college institutions can directly benefit from this collaboration. Because there is a lack of highly trained indigenous professionals and research on indigenous topics requires an extensive set of skills, support for indigenous students to gain experience 
in this research is also needed. In order to make space for culturally competent indigenous research, it was clear that conventional research paradigms needed to be more inclusive and flexible to meet the unique demands of this work. The extra resources and time needed to build trust, to travel to remote sites, and to meet the demands of academia, funding agencies, and indigenous communities were substantial. Structural supports for researchers who mediate these multiple demands are warranted to ensure that researchers are able to continue to do this work and focus on conducting research in a culturally competent and non-harming way.

The evidence that research with indigenous groups required personal and academic resources above and beyond conventional research poses several challenges. The striking mental health disparities present for indigenous groups are an indication of the effort needed for the improved well-being of indigenous groups. The importance of reciprocity, providing a service through research, and having tangible benefits for indigenous community members is integral for people for whom there is such a need for services. If additional resources and supports are not provided to bolster researchers and communities to work toward the improved well-being of indigenous groups, the understanding of these chronic disparities may not be uncovered. Researchers expressed the tendency of indigenous issues to be invisible to mainstream culture, and thus neglected. In order for the United States to meet their trust responsibility of health care to indigenous communities, culturally sensitive research must be conducted to understand indigenous issues. By building trust with indigenous communities and conducting research in a collaborative and culturally sensitive way, the reputation of research may be recast in a positive and credible light.

\section{Strengths, Limitations, and Suggestions for Future Researchers}

There are several limitations to this study. Because this is a purposive qualitative study, it cannot be generalized beyond these participants. Though participants from this study represented a heterogeneous and interdisciplinary cross-section of researchers, the perspectives of other researchers could vary. Because this study did not include researchers who attempted to conduct research with indigenous communities and did not succeed in this endeavor, the variability in their experiences is unknown. Finally, this study includes the perspectives of researchers only; replicating the study with indigenous community participants to see how their accounts match up would provide valuable additional insight and information.

Despite these limitations, this study has many strengths. It illuminates the lived experience of researchers working with indigenous groups. It incorporates numerous strategies to establish scientific rigor, which results in credible and trustworthy results. The descriptions of researchers' experiences demonstrates the considerable impact of history on indigenous people 
in the United States. The results demonstrate that when researchers prove to be trustworthy and safe, profound connections can develop. Although establishing trust is important in order to be able to conduct ethical research with indigenous communities, it is unknown whether trust building yields more effective research for indigenous communities. Future research that examines the impact of trust building on research effectiveness is needed to inform this question.

Researchers identified numerous suggestions for establishing trusting relationships with indigenous communities. Many researchers highlighted the importance of having positive intentions and being transparent and authentic in their interactions with indigenous communities. Demonstrating a willingness to commit to long-term work with indigenous communities and providing tangible benefits to communities also aided in trust building. Long-term commitment and qualities of flexibility and a sense of humor also aided in this process. Future researchers can learn from these experiences to foster strong research collaborations with indigenous communities. The considerable investment by researchers and indigenous communities could provide for rewarding and mutually beneficial experiences for both groups.

\section{REFERENCES}

Banner, S. (2005). How the Indians lost their land law and power on the frontier. Cambridge, MA: The Belknap Press of Harvard University Press.

Brave Heart, M. Y. H. (1999). Rebuilding the Lakota nation through addressing historical trauma among Lakota parents. Journal of Human Behavior in the Social Environment, 2(1/2), 109-126.

Brave Heart, M. Y. H., \& DeBruyn, L. M. (1998). The American Indian holocaust: Healing historical unresolved grief. American Indian $\&$ Alaska Native Research, $8(2), 60-82$.

Burns, N. (1989). Standards for qualitative research. Nursing Science Quarterly, 2, $44-52$.

Caldwell, J. Y., Davis, J. D., Du Bois, B., Echo-Hawk, H., Erickson, J. S., Goins, R. T., ... Stone, J. B. (2005). Culturally competent research with American Indians and Alaska Natives: Findings and recommendations of the work group on American Indian research and program evaluation methodology. American Indian E Alaska Native Research, 12(1), 1-21.

Capriccioso, R. (2010, April 21). Havasupai blood case settled. Indian Country Today. Retrieved from http://www.indiancountrytoday.com/archive/91728874. html.

Christopher, S., Watts, V., McGormic, A. K. H. G., \& Young, S. (2008). Building and maintaining trust in a community-based participatory research partnership. American Journal of Public Health, 98(8), 1398-1406.

Creswell, J. (1998). Qualitative inquiry and research design: Choosing among five traditions. Thousand Oaks, CA: Sage Publications, Inc. 
Creswell, J. (2007). Qualitative inquiry and research design: Choosing among five traditions (2nd ed.). Thousand Oaks, CA: Sage Publications, Inc.

Dé Ishtar, Z. (2004). Living on the ground research: Steps towards white women researching in collaboration with indigenous people. Hecate, 30(1), 72-82.

Dowling, M. (2007). From Husserl to van Manen. A review of different phenomenological approaches. International Journal of Nursing Studies, 44 , 131-142.

Fisher, P. A., \& Ball, T. J. (2003). Tribal participatory research: Mechanisms of a collaborative model. American Journal of Community Psychology, 32(3/4), 207-216.

Fisher, P. A., \& Ball, T. J. (2005). Balancing empiricism and local cultural knowledge in the design of prevention research. Journal of Urban Health, 82(2(3)), iii44-iii55.

Garrett, M. T., \& Pichette, E. F. (2000). Red as an apple: Native American acculturation and counseling with or without reservation. Journal of Counseling $\mathcal{E}$ Development, 78(1), 3-13.

Gilstrap, D. L. (2007). Phenomenological reduction and emergent design: Complementary methods for leadership narrative interpretation and metanarrative development. International Journal of Qualitative Methods, 6(1), $1-11$.

Groenewald, T. (2004). A phenomenological research design illustrated. International Journal of Qualitative Methods, 3(1), 1-26.

Holkup, P. A., Rodehorst, T. K., Willhelm, S. L., Kuntz, S. W., Weinert, C., Stepans, M. B. F., Salois, E. M., Bull, J. L. H., \& Hill, W. G. (2009). Negotiating three worlds: Academia, nursing science and tribal communities. Journal of Transcultural Nursing, 20, 164-175.

Kollock, P. (1994). The emergence of exchange structures: An experimental study of uncertainty, commitment, and trust. The American Journal of Sociology, 100(2), 313-345.

Kvale, S. (1983). The qualitative research interview: A phenomenological and hermeneutical mode of understanding. Journal of Phenomenological Psychology, 14(2), 171-196.

Legters, L. H. (1988). The American genocide. Policy Studies Journal, 16(4), 768777. doi: 10.1111/j.1541-0072.1988.tb00685.x.

Letiecq, B. L., \& Bailey, S. J. (2004). Evaluating from the outside: Conducting crosscultural evaluation research on an American Indian reservation. Evaluation Review, 28, 342-357.

Liu, S. (2008). Student interaction experiences in distance learning courses: A phenomenological study. Online Journal of Distance Learning Administration, 11(1), Retrieved from http://www.westga.edu/ distance/ ojdla/spring111/Liu111.html

Lopez, K. A., \& Willis, D. G. (2004). Descriptive versus interpretive phenomenology: Their contributions to nursing knowledge. Qualitative Health Research, 14(5), 726-735.

Moustakas, C. (1994). Phenomenological research methods. Thousand Oaks, CA: Sage Publications, Inc. 
National Institutes of Health (U.S.). (2009). Health disparities research LRP. Retrieved from http://www.lrp.nih.gov/about_the_programs/health_disparities.aspx.

Office of the General Counsel, U.S. Commission on Civil Rights. (2004). Native American health care disparities briefing: Executive summary. Juneau, AK: U.S. Commission on Civil Rights.

Salois, E. M., \& Holkup, P. A. (2006). Research as spiritual covenant. Western Journal of Nursing Research, 28(5), 505-563.

Smith, L. T. (1999). Decolonizing methodologies research and indigenous peoples. New York, NY: Zed Books Ltd.

Starks, H., \& Brown Trinidad, S. (2007). Choose your method: A comparison of phenomenology, discourse analysis, and grounded theory. Qualitative Health Research, 17, 1372-1380.

Struthers, R., \& Peden-McAlpine, C. (2005). Phenomenological research among Canadian and United States indigenous populations: Oral tradition and quintessence of time. Qualitative Health Research, 15(9), 1264-1276. doi: $10.1177 / 1040732305281329$.

van Manen, M. (1990). Researching lived experience. London, Ontario, Canada: State University of New York Press.

Walls, L. (2006). Mental health and substance abuse services preferences among American Indian people of the northern midwest. Community Mental Health Journal, 42(6), 521-535.

Weaver, H. N. (1997). The challenge of research in Native American communities: Incorporating principles of cultural competence. Journal of Social Services Research, 23(2), 1-15.

Weaver, H. N. (1998). Indigenous people in a multicultural society: Unique issues for human services. Social Work, 43(3), 203-211.

Whitbeck, L. B., Adams, G. W., Hoyt, D. R., \& Chen, X. (2004). Conceptualizing and measuring historical trauma among American Indian people. American Journal of Community Psychology, 33(3/4), 119-130.

Whitbeck, L. B. (2009). First Americans: Psychopathology and shortage of professionals. Journal of the American Academy of Child \& Adolescent Psychiatry, 48(1), 87-88. doi: 10.1097/CHI.0b013e3181908e6f.

Wilson, H. S., \& Hutchinson, S. A. (1991). Triangulation of qualitative methods: Heideggerian hermeneutics and grounded theory. Qualitative Health Research, 1, 263-276.

Yamagishi, T., Cook, K. S., \& Watabe, M. (1998). Uncertainty, trust, and commitment formation in the United States and Japan. American Journal of Sociology, 104(1), 165-194. 